\section{FEM celebrates its 80th Anniversary}

FEM, formerly known as the Forschungsinstitut für Edelmetalle und Metallchemie, in Schwäbisch Gmünd, Germany celebrated its 80th Anniversary on 19th September 2002, an event attended by the Economics Minister of the Landes Baden-Württemburg, Dr Walter Döring, other dignitaries of the region and the city of Schwäbisch Gmünd, and over 100 guests, including 2 former FEM directors and current members of staff.

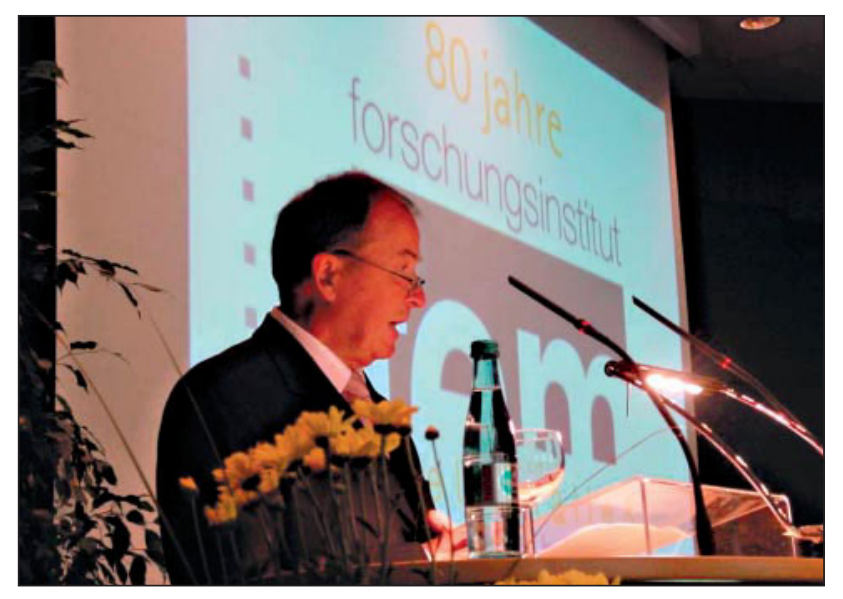

Figure 1

Mr Hasso Kaiser, Chairman of the FEM Board welcomes guests

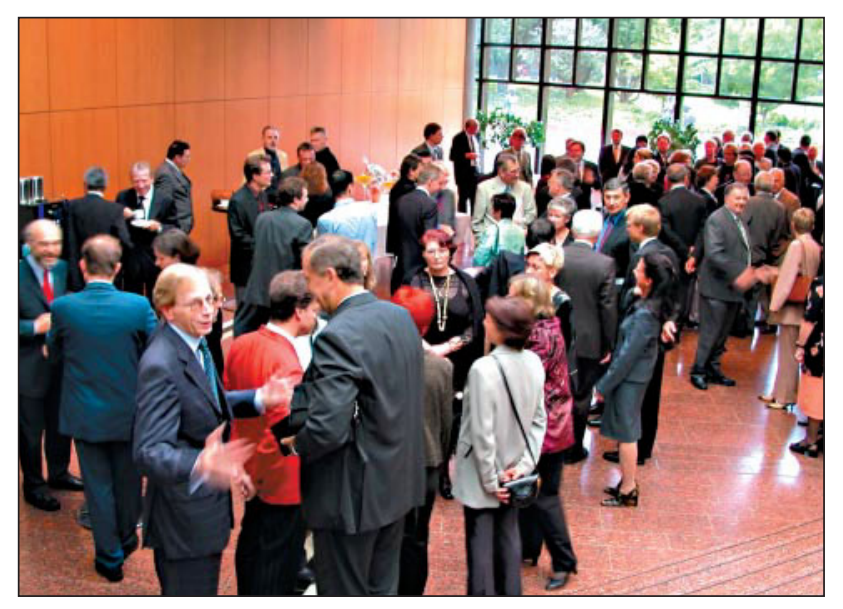

Figure 2

Guests mingling at the 80th Anniversary celebration

\section{The 80th Anniversary Celebration}

Following the introductory welcome by Mr Hasso Kaiser, chairman of the Board of FEM, Dr Döring gave an anniversary address in which the role of FEM as a competent part of the research infrastructure supported by government for the benefit of business was highlighted. His government's support for FEM has been amply demonstrated by the funding of a major refurbishment of the laboratories some 2 years ago and currently a new extension to the laboratories. This was followed by a thought-provoking lecture by Professor Franz Josef Radermacher, Forschungsinstitut für anwendugsorientierte Wissensverabeitung at Ulm on 'Questions for Germany and the World on the Future after the Rio and South Africa conferences' (on the protection of the environment, energy reduction and conservation of resources). One point made was that new technology has an important role to play but not alone. Governments and Society must think through the consequences and implications and make necessary adjustments to allow the technology to benefit society.

There followed several congratulatory addresses from the City of Schwäbisch Gmünd and from industry, including one from World Gold Council. There has been a long association between FEM and WCC - over 25 years - in which WCC has supported R \& D projects, particularly related to gold jewellery technology development. FEM is a centre of excellence with unique expertise and facilities and WCC foresaw its close relationship continuing over the next decade or two!

The afternoon was notable for the 'topping out' of the new extension to the FEM building. The extension will be finished and ready in mid-2003. Needless to say, the topping out ceremony was followed by a celebration in the traditional manner - a 'Richtfest' for staff and guests in the shell of the ground floor of the extension. Fortunately, the weather was kind!

\section{History of FEM}

Founded in 1922 in Schwäbisch Gmünd, a city about 50 km east of Stuttgart and one of 3 centres of the precious metals industry in Germany, the Forschungsinstitut für Edelmetalle und Metallchemie (Research Institute for Precious Metals and Metal Chemistry) had an initial mandate to carry out research into the metallurgy of the precious metals, assaying and training courses for the precious metals industry. In 1934, the Forschungsinstitut was headed by a new Director, Dr Ernst Raub, and it was under his leadership that it made many important contributions to the metallurgy and electroplating of the precious metals. The early history of the Forschungsinstitut has been recounted by Dr Leslie Hunt in this journal (L.B. Hunt, Gold Bulletin, vol. 8 (2), 1975, 56-59) to mark the 70th birthday of Dr Ernst Raub. 


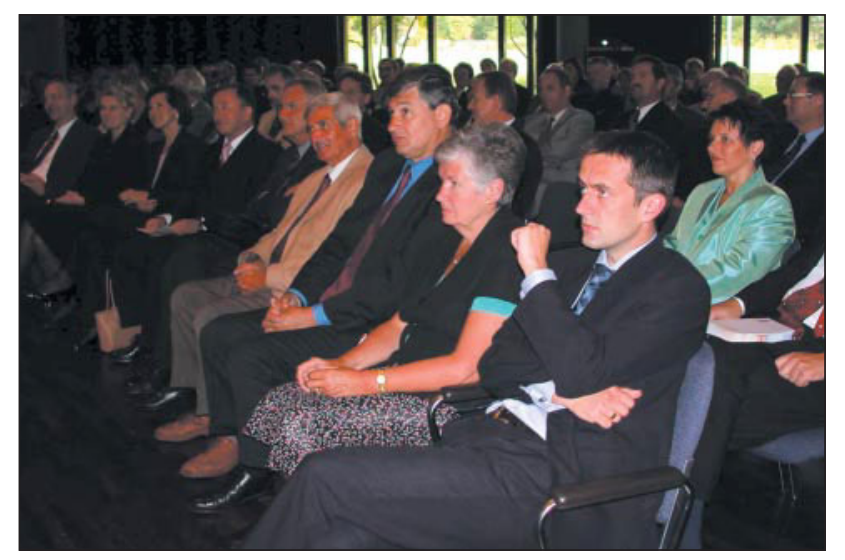

Figure 3

Drs Corti and Holliday, World Gold Council, in the audience

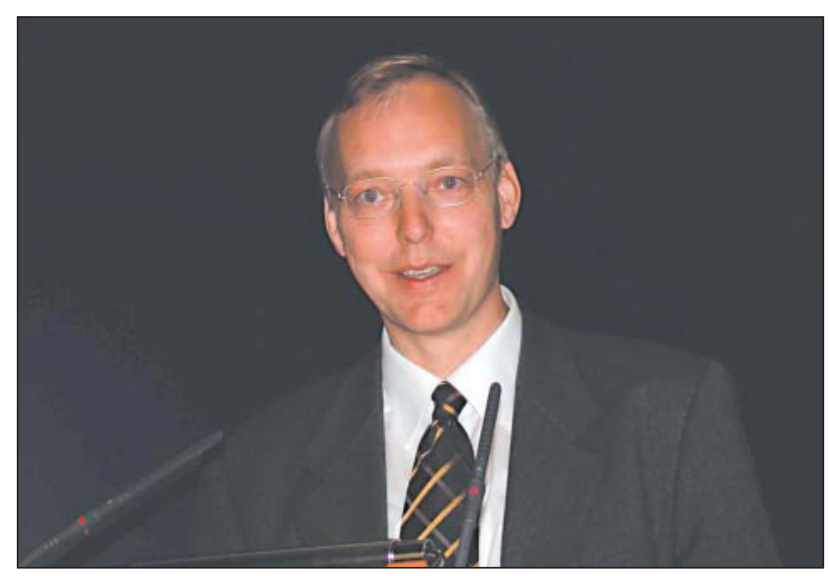

Figure 4

Dr Andreas Zielonka, Geschäftsführer, FEM

In 1970, his son, Professor Christoph Raub, took over as Director and the good work and the flow of scientific papers continued in both scope and volume. In his report of the 70th Anniversary of FEM, as it now became known, Dr Bill Rapson (Gold Bulletin, vol 25 (3), 1992, 104-109) noted that this broadening of the scope of its work had been facilitated by the continuing financial support from both Federal and State sources, the Deutsche Forschungsgemeinschaft, research associations and industry. He also remarked on its active programmes of technology transfer and its activities in precious metals metallurgy, properties and applications in dentistry, electronics and electrotechnology. As well as electroplating technologies, FEM was involved in thin film coatings by PVD and the anodic oxidation of the light metals. Allied to its relationship with the Max Planck Institute, it was also involved in research in superconductors. Other areas of activity included environmental protection, particularly the treatment of slimes and effluents, and archeometry, a continuing interest of Prof Christoph Raub even now in his retirement.

It was during this time that the major contribution to our understanding of the complexities of the Lost Wax casting

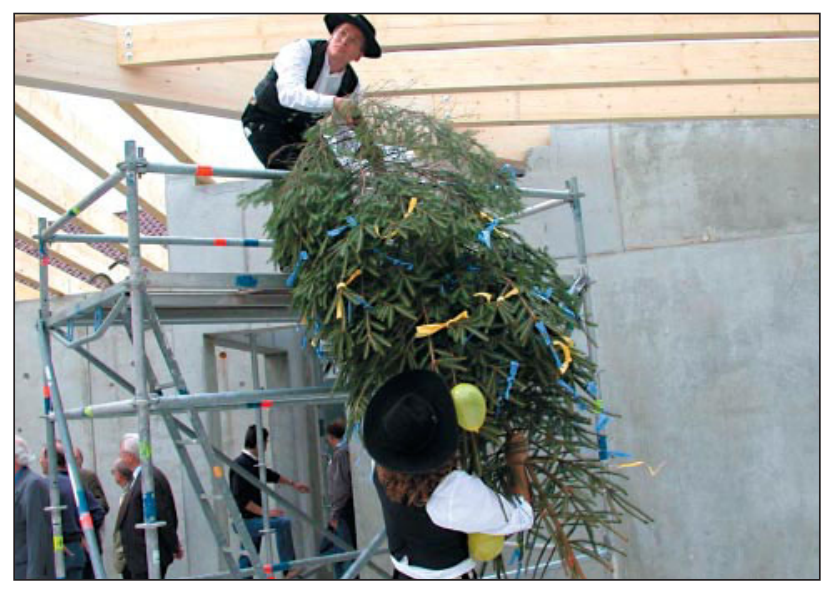

Figure 5

Preparing to 'top out' the new extension

process for jewellery manufacture was made by Prof. C.J. Raub and his co-workers, notably Dieter Ott. Much of this work has been published in Gold Bulletin, Aurum and Gold Technology, publications of World Gold Council and its predecessor, Intergold.

Professor Raub retired in 1995 and his role as director of FEM taken over by his deputy, Dr Hermann Jehn and, more recently, by Dr Andreas Zielonka. This period has coincided with a major refurbishment of the laboratories and upgrading of facilities, including a new conference room, named the Raubsaal. This year has seen the start of building of a new extension that will increase floor space by about $50 \%$ and will house the administrative functions, including the library facility, thus releasing valuable purpose-made space in the main building for laboratory use.

Dr C.W. Corti

Note: For further information on FEM and its activities, visit their website: www.fem-online.de

E-mail: fem@fem-online.de

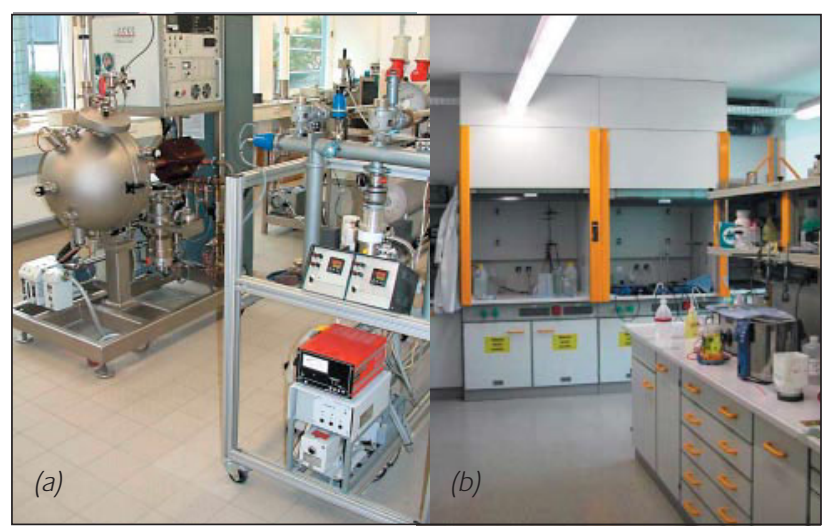

Figure 6

The refurbished laboratories (a) The investment casting laboratory (b) A chemical laboratory 